\title{
HUBUNGAN KARAKTERISTIK DAN PENGETAHUAN IBU HAMIL DENGAN PERILAKU HYGIENE TENTANG KEPUTIHAN (FLOUR ALBUS) DI PUSKESMAS KALUMPANG KOTA TERNATE TAHUN 2013
}

\author{
Nuzliati T Djama*), Amira BSA*)
}

\begin{abstract}
Knowledge relations of pregnant women with the hygiene behavior about flour albus in Puskesmas Kalumpang Ternate Oktober 2013

Whiteness or Flour Albus is an abnormal vaginal secretion in women. Many women are not aware that they regard whitish vaginal discharge as common and trivial. Survey of health workers at the Puskesmas Kalumpang Ternate Incidence of Flour Albus / Whitish in pregnant women and pregnant women about the knowledge of flour albus / whiteness, from $100 \%$ of pregnant women around 55\% of women do not know flour albus / discharge is physiological and pathological. The purpose of this study is to reveal Knowledge relations of pregnant women with the hygiene behavior about flour albus in Puskesmas Kalumpang Ternate Oktober 2013. The study design was descriptive correlational, design is cross sectional survey, with 30 samples of working mothers. The statistical analysis use in this study was bivariate. The results Relations knowledge of pregnant women with the hygiene behavior about flour albus in Puskesmas Kalumpang Ternate Oktober 2013, Based on the results showed a significant association $(\mathrm{p}=0.036)$. Based on the Knowledge relations of pregnant women with the hygiene behavior about flour albus in Puskesmas Kalumpang Ternate Oktober 2013, can be considered in an effort to increase knowledge and awareness of the importance of maintaining the cleanliness of the area of sex organs.
\end{abstract}

Keywords: knowledge, pregnant women, hygiene behavior, flour albus

\section{PENDAHULUAN}

Keputihan (Fluor Albus) merupakan salah satu alasan pada wanita yang paling sering untuk memeriksakan diri ke dokter, khususnya dokter ahli kebidanan dan penyakit kandungan (GBI, Prawiharjo, 2006). Keputihan (Flour Albus) dibagi menjadi dua jenis, yaitu keputihan fisiologis dan patologis. Fluor Albus/ keputihan fisiologis maupun patologis harus segera diobati karena masing-masing membawa pengaruh bagi kesehatan. Meskipun keputihan /Fluor Albus termasuk penyakit yang sederhana, kenyataannya Fluor Albus/ keputihan tidak mudah disembuhkan. Fluor Albus / keputihan menyerang sekitar $50 \%$ populasi wanita dan hampir mengenai semua umur. Menurut Maharani, lebih dari 75\% wanita di Indonesia mengalami keputihan / Fluor Albus, paling tidak satu kali dalam hidupnya. Hal ini berkaitan dengan cuaca yang lembab, yang mempermudah berkembangnya infeksi jamur dan bakteri patogen (Depkes, 2008).

Penelitian Emillana Citra dkk yang dilakukan di Puskesmas Jakarta, terdapat 163 penderita fluor albus yaitu 18 wanita $(11,0 \%)$ adalah ibu hamil, $3,7 \%$ pada kehamilan trimester I, 4,9\% pada kehamilan trimester II dan $2,5 \%$ pada kehamilan trimester III. Sedangkan di BKIA RS Tipe B terdapat 380 pasien ibu hamil yang memeriksakan kehamilannya pada tahun 2008 dan ada sebanyak 90 orang $(23,7 \%)$ yang mengeluh flour albus. Selain berkaitan dengan kebiasaan sehari-hari salah satu faktor penyebab terjadinya flour albus (keputihan) juga karena rendahnya pengetahuan ibu hamil tentang keputihan dengan demikan pentingnya penyuluhan mengenai Flour albus (keputihan) pada wanita khususnya ibu hamil perlu ditingkatkan mengingat tingginya angka kejadian flour albus yang setiap tahunnya semakin bertambah. Penelitian yang dilakukan oleh Eni, pada bulan maret tahun 2009 dari 20 responden yang terlihat dalam penelitian 10 orang $(50 \%)$ memiliki pengetahuan cukup, 9 orang $(45 \%)$ memiliki pengetahuan baik dan 8 orang (40\%) memiliki pengetahuan kurang. Berdasarkan hasil penelitian diketahui bahwa umumnya ibu hamil yang menjadi responden mempunyai pengetahuan yang kurang tentang flour albus (keputihan).

Penelitian Emillana Citra dkk yang dilakukan di Puskesmas Jakarta, terdapat 163 penderita fluor albus yaitu 18 wanita $(11,0 \%)$ adalah ibu hamil, $3,7 \%$ pada kehamilan trimester I, 4,9\% pada kehamilan trimester II dan 2,5\% pada kehamilan trimester III. Sedangkan di BKIA RS Tipe B terdapat 380 pasien ibu hamil yang memeriksakan kehamilannya pada tahun 2008 dan ada sebanyak 90 orang $(23,7 \%)$ yang mengeluh flour albus. Selain berkaitan dengan kebiasaan sehari-hari salah satu faktor penyebab terjadinya flour 
albus (keputihan) juga karena rendahnya pengetahuan ibu hamil tentang keputihan dengan demikan pentingnya penyuluhan mengenai Flour albus (keputihan) pada wanita khususnya ibu hamil perlu ditingkatkan mengingat tingginya angka kejadian flour albus yang setiap tahunnya semakin bertambah. Penelitian yang dilakukan oleh Eni, pada bulan maret tahun 2009 dari 20 responden yang terlihat dalam penelitian 10 orang $(50 \%)$ memiliki pengetahuan cukup, 9 orang $(45 \%)$ memiliki pengetahuan baik dan 8 orang (40\%) memiliki pengetahuan kurang. Berdasarkan hasil penelitian diketahui bahwa umumnya ibu hamil yang menjadi responden mempunyai pengetahuan yang kurang tentang flour albus (keputihan).

Berdasarkan pokok permasalahan diatas, maka penulis ingin mengetahui "Hubungan karakteristik dan pengetahuan ibu hamil dengan perilaku hygiene tentang flour albus (keputihan) di Puskesmas Kalumpang Kota Ternate bulan Oktober 2013”.

\section{Tujuan Penelitian}

Tujuan Umum

\section{Kerangka Konsep}

\begin{tabular}{|l|}
\hline $\begin{array}{l}\text { Tingkat } \\
\text { pengetahuan ibu } \\
\text { hamil tentang flour } \\
\text { albus }\end{array}$ \\
\hline \\
\hline Karekteristik Ibu: \\
1. Usia Kehamilan \\
2. Paritas \\
3. Pendidikan \\
4. Pekerjaan \\
\hline
\end{tabular}

\section{METODOLOGI PENELITIAN}

Meode yang digunakan dalam penelitian ini deskriptif adalah metode penelitian. Rancangan penelitian ini merupakan suatu survey cross sectional, yaitu suatu penelitian untuk mempelajari dinamika korelasi antara faktor-faktor risiko dengan efek, dengan cara pendekatan, observasi atau pengumpulan data sekaligus pada suatu saat.
Tujuan umum dari penelitian adalah untuk diketahuinya hubungan pengetahuan ibu hamil dengan perilaku hygiene tentang flour albus (keputihan) di Puskesmas Kalumpang Kota Ternate.

\section{Tujuan Khusus}

1. Diketahui gambaran Karakteristik Ibu Hamil yang meliputi Usia Kehamilan, Paritas, Pendidikan dan Pekerjaan. tentang flour albus (keputihan) di Puskesmas Kalumpang Kota.

2. Diketahuinya gambaran Pengetahuan dan Perilaku Ibu Hamil tentang flour albus (keputihan) di Puskesmas Kalumpang Kota Ternate.

3. Diketahuinya Hubungan antara Karakteristik dengan Perilaku Ibu Hamil tentang flour albus (keputihan) di Puskesmas Kalumpang Kota Ternate.

4. Diketahuinya Hubungan antara Pengetahuan dan Perilaku Ibu Hamil tentang flour albus di Puskesmas.
Perilaku Hygiene Tentang flour Albus
Dalam penelitian ini peneliti ingin mengetahui hubungan karakteristik dan pengetahuan ibu hamil dengan perilaku hygiene tentang fluor albus (keputihan) di Puskesmas Kalumpang Kota Ternate bulan Oktoberr 2013.

\section{Hasil Penelitian}

Mengetahui pengetahuan ibu hamil tentang keputihan (flour albus) di Puskesmas Kalumpang Kota Ternate, dilakukan survey langsung terhadap 30 orang responden menggunakan kuesioner. Hasil penelitian tersebut dapat dilihat pada tabel berikut: 


\section{Analisis Univariat}

a. Pengetahuan Ibu hamil Tentang Flour Albus

Tabel 1 Distribusi frekuensi Pengetahuan Ibu Hamil tentang flour albus di Puskesmas Kalumpang Kota Ternate Oktober 2013

\begin{tabular}{ccc}
\hline Pengetahuan & Frekuensi & $\%$ \\
\hline Kurang & 11 & 36,7 \\
Cukup & 14 & 46,7 \\
Baik & 5 & 16,6 \\
\hline Total & 30 & 100
\end{tabular}

Tabel 1 menunjukkan Subjek penelitian adalah 30 orang ibu hamil. Tabel 1 menunjukkan 11 orang $(36,7 \%)$ termasuk kategori kurang, sebanyak 14 orang

$(46,7 \%)$ kategori cukup dan 5 orang $(16,6 \%)$ kategori baik terhadap pengetahuan ibu hamil tentang flour albus di Puskesmas Kalumpang Kota Ternate.

\section{b. Usia Kehamilan}

Tabel 2 Distribusi frekuensi Usia Kehamilan Ibu Hamil tentang flour albus di Puskesmas Kalumpang Kota Ternate Oktober 2013

\begin{tabular}{ccc}
\hline Usia Kehamilan & Frekuensi & $\%$ \\
\hline Trimester I & 7 & 23,3 \\
Trimester II & 19 & 63,3 \\
Trimester III & 4 & 13,4 \\
\hline Total & 30 & 100 \\
\hline
\end{tabular}

Tabel 2 menunjukkan 7 orang $(23,3 \%) \quad$ kategori Trimester 2 dan 4 orang $(13,4 \%)$ kategori kategori Trimester 1 , sebanyak 19 orang $(63,3 \%) \quad$ Trimester 3 terhadap usia kehamilan ibu hamil

c. Paritas

Tabel 3 Distribusi frekuensi Paritas Ibu Hamil tentang flour albus di Puskesmas Kalumpang Kota Ternate Oktober 2013

\begin{tabular}{ccc}
\hline Paritas & Frekuensi & $\%$ \\
\hline 1 & 13 & 43,3 \\
$2-3$ & 14 & 46,7 \\
$>3$ & 3 & 10,0 \\
\hline Total & 30 & 100 \\
\hline
\end{tabular}

Tabel 3 menunjukkan 13 orang $(43,3 \%)$ kategori paritas 1, 14 orang $(46,7 \%)$ kategori paritas 2-3 dan sisanya sebanyak 3 orang (10\%) paritas $>3$ pada ibu hamil. 


\section{d. Pendidikan}

Tabel 4 Distribusi frekuensi Pendidikan Ibu Hamil tentang flour albus di Puskesmas Kalumpang Kota Ternate Oktober 2013

\begin{tabular}{ccc}
\hline Pendidikan & Frekuensi & $\%$ \\
\hline Tidak Sekolah & 3 & 10 \\
SD & 5 & 16,7 \\
SMP & 8 & 26,7 \\
SMA & 12 & 40 \\
PT & 2 & 6,6 \\
\hline Total & 30 & 100 \\
\hline
\end{tabular}

Tabel 4 menunjukkan 3 orang (10\%) kategori Tidak Sekolah, 5 orang $(16,7 \%)$ dalam kategori SD, 8 orang $(26,7 \%)$ kategori SMP, 12 orang

(40\%) kategori SMA dan sisanya sebanyak 2 orang $(6,6 \%)$ tergolong dalam kategori PT pada ibu hami

e. Pekerjaan

Tabel 5 Distribusi frekuensi Pekerjaan Ibu Hamil tentang flour albus di Puskesmas Kalumpang KotaTernate Oktober 2013

\begin{tabular}{ccc}
\hline Pekerjaan & Frekuensi & $\%$ \\
\hline IRT & 20 & 66,7 \\
PNS & 3 & 10 \\
Wiraswasta & 7 & 23.3 \\
\hline Total & 30 & 100 \\
\hline
\end{tabular}

Tabel 5 menunjukkan 20 orang $(23,3 \%)$ kategori Wiraswasta pada ibu hamil. $(66,7 \%)$ termasuk dalam kategori IRT, 3 orang (10\%) kategori PNS dan sisanya sebanyak 7 orang

\section{f. Perilaku}

Tabel 6 Distribusi frekuensi Perilaku Ibu Hamil tentang flour albus di Puskesmas Kalumpang Kota Ternate Oktober 2013

\begin{tabular}{ccc}
\hline Perilaku & Frekuensi & $\%$ \\
\hline Tidak baik & 21 & 70 \\
Baik & 9 & 30 \\
\hline Total & 30 & 100 \\
\hline
\end{tabular}

Tabel 6 menunjukkan21 orang $(70 \%)$ sebanyak 9 orang (30\%) tergolong kategori Baik pada termasuk kategori Tidak Baik dan sisanya ibu hamil. 


\section{Analisis Bivariat}

a. Hubungan Karakteristik dan Pengetahuan Ibu Hamil dengan Perilaku Hygiene

Tabel 7 Hubungan Karekteristik dan Pengetahuan Ibu Hamil dengan Perilaku Hygiene tentang flour albus di Puskesmas Kalumpang Kota Ternate Oktober 2013

\begin{tabular}{|c|c|c|c|c|c|c|c|c|}
\hline \multirow{3}{*}{ No } & \multirow{3}{*}{ Variabel } & \multicolumn{4}{|c|}{ Perilaku } & \multirow{2}{*}{\multicolumn{2}{|c|}{ Jumlah }} & \multirow{3}{*}{$\mathrm{F}$} \\
\hline & & \multirow{2}{*}{$\begin{array}{l}\text { Tidak } \\
\mathrm{F}\end{array}$} & \multirow{2}{*}{$\frac{\text { Baik }}{\%}$} & \multicolumn{2}{|c|}{ Baik } & & & \\
\hline & & & & $\mathrm{F}$ & $\%$ & $\mathrm{~F}$ & $\%$ & \\
\hline 1 & Pengetahuan & & & & & & & \\
\hline & Kurang & 9 & 30 & 2 & 6,7 & 11 & 36,7 & \\
\hline & Cukup & 9 & 30 & 5 & 16,6 & 14 & 46,6 & 0,036 \\
\hline & Baik & 3 & 10 & 2 & 6,7 & 5 & 16,7 & \\
\hline
\end{tabular}

Tabel 7 menunjukkan hasil uji statistik $\mathrm{p}=0,036$ yang artinya ada hubungan yang bermakna antara pengetahuan ibu hamil

dengan perilaku hygiene tentang flour albus ( keputihan).

\section{b. Hubungan Karakteristik Ibu Hamil dengan Perilaku Hygiene}

Tabel 8 Hubungan Karekteristik Ibu Hamil dengan Perilaku Hygiene tentang flour albus di Puskesmas Kalumpang Kota Ternate Oktober 2013

\begin{tabular}{|c|c|c|c|c|c|c|c|c|}
\hline \multirow{3}{*}{ No } & \multirow{3}{*}{ Variabel } & \multicolumn{4}{|c|}{ Perilaku } & \multirow{2}{*}{\multicolumn{2}{|c|}{ Jumlah }} & \multirow{3}{*}{$\mathrm{P}$} \\
\hline & & \multicolumn{2}{|c|}{ Tidak Baik } & \multicolumn{2}{|c|}{ Baik } & & & \\
\hline & & Frek & $\%$ & Frek & $\%$ & Frek & $\%$ & \\
\hline \multirow[t]{4}{*}{1} & Usia kehamilan & & & & & & & \\
\hline & Trimester I & 4 & 13,3 & 3 & 10 & 7 & 23,3 & \\
\hline & Trimester II & 14 & 46,7 & 5 & 16,7 & 19 & 63,3 & 0,047 \\
\hline & Trimester III & 3 & 10 & 1 & 3,3 & 4 & 13,4 & \\
\hline \multirow[t]{4}{*}{2} & Paritas & & & & & & & \\
\hline & 1 & 8 & 26,7 & 5 & 16,7 & 13 & 14,3 & \\
\hline & $2-3$ & 10 & 33,3 & 4 & 13,3 & 14 & 46,7 & 0,042 \\
\hline & $>3$ & 3 & 10 & 0 & 0 & 3 & 10 & \\
\hline \multirow[t]{6}{*}{3} & Pendidikan & & & & & & & \\
\hline & Tidak Sekolah & 1 & 3,3 & 2 & 6,7 & 3 & 10 & \\
\hline & SD & 4 & 13,3 & 1 & 3,3 & 5 & 16,7 & \\
\hline & SMP & 7 & 23,3 & 1 & 3,3 & 8 & 26,7 & 0,044 \\
\hline & SMA & 8 & 26,7 & 4 & 13,3 & 12 & 40 & \\
\hline & PT & 1 & 3,3 & 1 & 3,3 & 2 & 6,6 & \\
\hline \multirow[t]{4}{*}{4} & Pekerjaan & & & & & & & \\
\hline & IRT & 14 & 46,7 & 6 & 20 & 20 & 66,7 & 0,048 \\
\hline & PNS & 2 & 6,7 & 1 & 3,3 & 3 & 10 & \\
\hline & Wiraswasta & 5 & 16,7 & 2 & 6,7 & 7 & 23,3 & \\
\hline
\end{tabular}

Tabel 8 Kategori usia kehamilan dengan perilaku hygiene menunjukkan hasil uji statistik $\mathrm{p}=0,047$ yang artinya ada hubungan yang bermakna antara usia kehamilan dengan perilaku hygiene tentang flour albus (keputihan) pada ibu hamil, pada kategori paritas dengan perilaku hygiene menunjukan hasil uji statistik $\mathrm{p}=0,042$ hal ini berarti ada hubungan yang bermakna antara paritas dengan perilaku hygiene tentang flour albus pada ibu hamil. Kategori pendidikan dengan perilaku hygiene dengan hasil uji statistik $\mathrm{p}=0,044$ berarti ada hubungan yang bermakna antara 
pendidikan dengan perilaku hygiene tentang flour albus. Selanjutnya pada variabel pekerjaan ibu hamil dengan perilaku hygiene menunjukkan hasil uji statistik $\mathrm{p}=0,048$ yang

\section{PEMBAHASAN}

1. Hubungan Karakteristik Ibu Hamil Dengan Perilaku Hygiene Tentang Keputihan (flour albus) di Puskesmas Kalumpang Kota Ternate

a. Hubungan Usia Kehamilan Dengan Perilaku Hygiene Tentang Keputihan (flour albus).

Survey yang di lakukan langsung terhadap 30 orang responden menggunakan kuesioner. Berdasarkan hasil uji statistik karakteristik ibu hamil dengan perilaku hygiene tentang keputihan (flour albus) di Puskesmas Kalumpang Kota Ternate pada tabel 5.8 diatas, pada kategori hubungan usia kehamilan dengan perilaku menunjukkan hubungan yang bermakna ( $\mathrm{p}=0,047<0.05)$.

Dari hasil uji statistik di atas terdapat hubungan yang signifikan atau bermakna antara usia kehamilan dengan perilaku hygiene tentang keputihan (flour albus) di Puskesmas Kalumpang Kota Ternate, pada usia kehamilan ditemukan angka tertinggi pada trimester kedua di mana terjadi peningkatan hormone estrogen dan pola makan yang tidak teratur.

b. Hubunga Paritas Ibu Hamil Dengan Perilaku Hygiene Tentang Keputihan (flour albus).

Berdasarkan hasil uji statistik karakteristik ibu hamil dengan perilaku hygiene tentang keputihan (flour albus) di Puskesmas Kalumpang Kota Ternate pada tabel diatas, pada kategori hubungan paritas dengan perilaku menunjukkan hubungan yang bermakna $(\mathrm{p}=0,042)$. Hasil ini menunjukkan adanya hubungan yang bsignifikan antara paritas dengan perilaku hygiene tentang keputihan (flour albus). Dengan demikian dapat disimpulkan bahwa jumlah anak (paritas) pada ibu hamil tidak menjamin seseorang berprilaku lebih baik terutama tentang keputihan berarti ada hubungan yang bermakna antara pekerjaan dengan perilaku hygiene tentang flour albus( keputihan) pada ibu hamil

(flour albus).

c. Hubungan Pendidikan Dengan Perilaku Hygiene Tentang Keputihan (flour albus).

Hasil uji statistik karakteristik ibu hamil dengan perilaku hygiene tentang keputihan (flour albus) di Puskesmas Kalumpang Kota Ternate pada tabel 5.8 diatas, pada kategori hubungan pendidikan dengan perilaku menunjukkan hubungan yang bermakna ( $\mathrm{p}=$ 0,044). Hasil ini menunjukkan terdapat hubungan antara pendidikan dengan perilaku hygiene tentang keputihan (flour albus).

d. Hubungan Pekerjaan Dengan Perilaku Hygiene Tentang Keputihan (flour albus).

Berdasarkan hasil uji chi-square karakteristik ibu hamil dengan perilaku hygiene tentang keputihan (flour albus) di Puskesmas Kalumpang Kota Ternate bulan pada tabel diatas, pada kategori hubungan pekerjaan dengan perilaku menunjukkan hubungan yang bermakna $(p=0,048)$. terdapat hubungan yang signifikan antara pekerjaan dengan perilaku hygiene tentang keputihan (flour albus).dari hasil penelitian ini menunjukkan bahwa kesibukkan dalam pekerjaan dapat mengurangi perhatian seseorang mengenai kesehatannya terutama kehsehatan reproduksi. Menurut Thomas (2008), bekerja umumnya merupakan kegiatan yang menyita waktu. Bekerja bagi ibu-ibu akan mempunyai pengaruh kehidupan keluarga dan dapat menyita waktu.

\section{Hubungan Pengetahuan Ibu Hamil} Dengan Perilaku Hygiene Tentang Keputihan (flour albus) di Puskesmas Kalumpang Kota Ternate.

Hubungan pengetahuan ibu hamil dengan perilaku hygiene tentang keputihan (flour albus) di Puskesmas Kalumpang Kota Ternate dilakukan survey langsung terhadap 30 orang responden menggunakan kuesioner. Berdasarkan hasil uji statistik hubungan pengetahuan ibu hamil dengan perilaku hygiene tentang keputihan (flour albus) di Puskesmas Kalumpang Kota Ternate menunjukkan hubungan yang bermakna $(p=$ 
0,036). Ini menunjukkan terdapat hubungan yang signifikan antara pengetahuan dengan perilaku hygiene tentang keputihan (flour albus).

\section{KESIMPULAN DAN SARAN}

\section{Kesimpulan}

1. Pada Karakteristik :

a. Terdapat hubungan yang signifikan antara usia kehamilan (nilai $\mathrm{p}$ value 0,047),dengan perilaku hygiene tentang keputihan (flour albus) dan Pendidikan (nilai $\mathrm{p}$ valie 0,044 ) dengan perilaku tentang keputihan (flour albus ).

b. Terdapat hubungan yang bermakna antara Paritas (nilai $p$ value 0,42), dengan perilaku hygiene tentang keputihan (flour albus) dan pekerjaan (nilai $\mathrm{p}$ value 0,048 ) dengan perilaku hygiene tentang keputihan (flour albus)

2. Adanya hubungan yang signifikan antara Pengetahuan (nilai $\mathrm{p}$ value 0,036 ) dengan Perilaku hygiene tentang keputihan ( flour albus) serta Pengetahuan dan Perilaku Ibu Hamil tentang (keputihan) (flour albus)di Puskesmas Kalumpang Kota Ternate.

3. Adanya Hubungan antara Karakteristik dengan Pengetahuan dan Perilaku Ibu Hamil tentang keputihan (flour albus) di Puskesmas Kalumpang Kota Ternate.

4. Adanya hubungan antara

\section{Saran}

1. Bagi Ibu hamil diharapkan agar dapat menambah pengetahuan mengenai keputihan (flour albus) dan cara mengatasinya.

2. Bagi Puskesmas Kalumpang Kota Ternate diharapkan agar dapat memberikan informasi - informasi melalui kegiatan penyuluhan mengenai flour albus dan penanganannya kepada ibu hamil.

3. Bagi Peneliti Selanjutnya

Diharapkan agar dapat melanjutkan penelitian mengenai keputihan (Flour Albus) sehingga menambah bahan wacana untuk para pembaca atau peneliti selanjutnya se.tublikasia dapat mempublikasikannya pada masyarakat.

\section{DAFTAR PUSTAKA}

Badriah, Dewi L. 2006. Metodologi Penelitian Ilmu-Ilmu Kesehatan. Multazam. Bandung

Bidan ku delima. Di akses 09 september 2011. pada http :// www.google.co.id.

Depkes RI 2006. Kesehatan Reproduksi wanita. Di akses 13 April 2009. Pada http :// gilib. unimus. AC. Id.

Depkes RI 2008. Angka Kejadian Perawatan Organ Reproduksi. Jakarta Di akses 21 juni 2010. Pada http ://gilib. Unimus. Ac. Id.

Depdiknas, 2006. Filosofi Perilaku. Di akses 25 mei 2012. Pada www.wikipedia.Com

GBI, Prawiharjo, 2006. Memahami Kesehatan Reprodukasi. Edisi pertama EGC Jakarta: EGC.

Hidayat. A. A. 2007. Metode Penelitian kebidanan Teknik analisis Data. Salemba Medika . Jakarta.

M. Shadine, 2009. Vulva Higiene terhadap daerah Kewanitaan. Tridasa Printer. Jakarta.

Manuaba, GBI. 2006. Memahami Kesehatan Reprodukasi. Edsi kedua. EGC. Jakarta. 